\title{
Brain injury following cardiac arrest: pathophysiology for neurocritical care
}

\author{
Hiroyuki Uchino ${ }^{1 *}$, Yukihiko Ogihara' ${ }^{1}$, Hidekimi Fukui ${ }^{1}$, Miyuki Chijiiwa' ${ }^{1}$ Shusuke Sekine ${ }^{1}$, Naomi Hara ${ }^{1}$
} and Eskil Elmér ${ }^{2}$

\begin{abstract}
Cardiac arrest induces the cessation of cerebral blood flow, which can result in brain danatge. The primary intervention to salvage the brain under such a pathological condition is to restore the cerebral blood flow to the ischemic region. Ischemia is defined as a reduction in blood flow to a level that is sufficient to alter normal cellular function. Brain tissue is highly sensitive to ischemia, such that even brief ischemic periods in neurons can initiate a complex sequence of events that may ultimately culminate in cell death. However, paradoxically, restoration of blood flow can cause additional damage and exacerbate the neurocognitive deficits in patients who suffered a brain ischemic event, which is a phenomenon referred to as "reperfusion injury." Transient brain ischemia followying cardiac arrest results from the complex interplay of multiple pathways including excitotoxicity, acidptoxicity, ionic imbalance, peri-infarct depolarization, oxidative and nitrative stress, inflammation, and apoptosis. The pathophysiology of post-cardiac arrest brain injury involves a complex cascade of molecular events, most of which remain unknown. Many lines of evidence have shown that mitochondria suffer severe damage in response to ischemic injury. Mitochondrial dysfunction based on the mitochondrial permeability transition after repeffusion, particularly involving the calcineurin/immunophilin signal transduction pathway, appears to play a pivotal role in the induction of neuronal cell death. The aim of this article is to discuss the underlying pathophysiology of brain damage, which is a devastating pathological condition, and highlight the central signal transduction pathway involved in brain damage, which reveals potential targets for therapeutic intervention.
\end{abstract}

Keywords: Pathophysiology of ischemic brain damage, Cardiac arrest, Post-cardiac arrest syndrome (PCAS), Mitochondrial dysfunction, Reperfusion injury, Excitotoxicity, Mitochondrial permeability transition (MPT),

Calcineurin/immunophilin

\section{Introduction}

Out-of-hospital cardiac arrest (OHCA) is a common initial disease in developed countries. According to the latest report, of the 123,987 patients with OHCA in Japan brought to the hospital, 75,397 patients were suffering from a cardiogenic cause. The survival rate of the patients with bystander at 1 month was $11.9 \%$ and the survival rate to hospital discharge was only $7.9 \%$ (http://www.fdma.go.jp/ neuter/topics/kyukyukyujo_genkyo/h26/01_kyukyu.pdf).

Patients who achieve return of spontaneous circulation (ROSC) after OHCA show significant morbidity and mortality due to the cerebral and cardiac dysfunction

\footnotetext{
* Correspondence: h-uchi@tokyo-med.ac.jp

'Department of Anesthesiology, Tokyo Medical University, 6-7-1 Nishishinjuku,

Shinjuku-ku, Tokyo 160-0023, Japan

Full list of author information is available at the end of the article
}

that leads to prolonged whole-body ischemia. This syndrome, called the post-cardiac arrest syndrome (PCAS), comprises anoxic brain injury, post-cardiac arrest myocardial dysfunction, systemic ischemia/reperfusion response, and persistent precipitating pathology. Cardiac arrest is often associated with neurological deterioration. Although many years of laboratory and clinical research have been spent, post-cardiac arrest brain injury (PBI), a key factor of PCAS that involves complex molecular mechanisms, remains a common cause of morbidity and mortality. The four key components of PCAS were identified as (1) PBI, (2) post-cardiac arrest myocardial dysfunction, (3) systemic ischemia/reperfusion response, and (4) persistent precipitating pathology [1]. Many studies have examined the mechanisms involved in ischemic brain injury. However, no effective pharmacological 
treatment directed at tissues of the central nervous system (CNS) has been established to prevent the pathological conditions that occur as a consequence. Therefore, all aspects of the basic mechanisms responsible for brain damage require urgent elucidation. Recently, our research has aimed towards understanding the involvement and importance of calcium and the calcineurin/immunophilin signal transduction pathway in brain damage. We previously demonstrated that immunosuppressants interacting with the calcineurin/immunophilin signal transduction pathway show potent neuroprotective effects in several animal models of ischemic brain damage, and these effects are considered to be separate from their action on immunocompetent cells [2-6].

In clinical anesthesiology, the pathological conditions that involve neuronal degeneration can be broadly divided into several categories as follows: (i) global ischemia due to an extended period of cardiac arrest $[7,8]$; (ii) cerebral infarction (focal ischemia) that occurs after the occlusion of cerebral arteries; (iii) direct injuries due to head trauma and cerebral compression associated with hematoma or cerebral edema; (iv) increased intracranial pressure and secondary hypoxic brain damage due to cerebrovascular spasm; (v) encephalitis or meningitis caused by viruses, bacteria, parasites, fungi, and spirochetes; and (vi) seizures caused by head trauma, cerebral tumors, cerebrovascular disorders, intracranial infections, and abnormal metabolism. This condition is likely to share many aspects of the pathological mechanisms resulting in brain damage and neurological impairment. Although the most crucial mechanisms responsible for the induction of brain damage remain undlear, it has been suggested that mitochondrial dysfunction is significantly involved. The elucidation of the basic pathophysiology for each of these pathological conditions that involve neuronal degeneration is of great importance for the development of effective neuroprotective pharmaceutical agents.

In this review, we outline the role of major pathophysiological disturbances leading to PBI and PCAS due to cardiac arrest that involve increased intracellular calcium, reactive oxygen species (ROS), and inflammation in ischemic neuronal cell death, with special emphasis on the mitochondrial permeability transition (MPT), which is a pathological state of the inner mitochondrial membrane leading to bioenergetic failure [9-12].

\section{Review}

\section{Pathophysiology of post-cardiac arrest brain injury and delayed neurodegeneration}

At the onset of cardiac arrest, cerebral blood flow tends to approach zero. In response to the stress of global ischemia, various cytokines and complement anaphylatoxins are synthesized and released. During cardiopulmonary resuscitation (CPR), blood flow is partially restored. Optimal CPR can restore the cardiac output to between 25 and $40 \%$ of pre-arrest values, while the brain receives $30 \%$ of this amount [13]. After onset of reperfusion, the activation of blood coagulation leads to the formation of microemboli, while the activated neutrophils and platelets accumulate in microvessels [14]. Cerebral microvascular blood flow may further be compromised by the a 1 adrenergic agonist action of endogenous or exogenous adrenaline which reduces capillary blood flow and increases arterial lactate levels [15]. During reperfusion, the generated ROS intensify endothelial injury increasing the exchange vessel's permeability and microvascular filtration [14].

After ROSC, a transient increase, in circulating catecholamine concentrations results in a normal or elevated blood pressure immediately, and high pressure periods are needed to overcome the potential no-reflow phenomenon. Several cytokines, which directly inhibit adrenal cortisol synthesis and increase the risk of early refractory shock, are upregulated which promote tissue damage due to neutrophil infiltration [16]. The ATPgenerating capacity of the mitochondria and energy charge of the tissue increase and are normalized after $1 \mathrm{~h}$ of reperfusion [17]. Lactate accumulation occurs during cardiac arrest and CPR; it is an essential aerobic energy substrate and contributes to neuronal integrity post-ischemia. Lactate is the main oxidizable energy substrate utilized by the brain, at least during the initial moments after ROSC.

The conditions after ROSC favor the opening of the mitochondrial permeability transition pore (mtPTP) which is now characterized by non-specific permeabilization of the inner mitochondrial membrane, resulting in a dramatic swelling of the mitochondria, followed by disruption of the outer membrane, particularly in the reperfused tissues [10]. The opening of mtPTP activates processes that lead to a delayed neuronal death after 24-48 h of recovery.

The levels of various interleukins are intensely increased and reach their peak concentration in the blood approximately $3 \mathrm{~h}$ after ROSC, indicating a "systemic inflammatory response syndrome" [18] during the early post-arrest phase. The impact of ischemia/reperfusion injury on brain injury increases with aging [19]. The impairment of brainstem function in aged patients may further deteriorate, resulting in increased mortality and morbidity following cardiac arrest and resuscitation.

Pathophysiological disorders occur from the onset of cardiac arrest; however, the clinical manifestations of neuronal degeneration are delayed. Massive functional neurological impairment may occur after ROSC, and morphological changes in the brain reach maximum levels after 3 weeks. The pathogenesis of delayed neuronal injury 
is further complicated by the fact that it occurs even in successfully recirculated brains. The post-ischemic hypoperfusion syndrome may evolve due to the mismatch between blood flow and oxygen requirements of the tissue.

\section{Induction of ischemic neuronal cell death-the glutamate- $\mathrm{Ca}^{2+}$ theory}

Ischemia is defined as a reduction in blood flow to a level that is sufficient to alter normal cellular function. Brain tissue is highly sensitive to ischemia, such that even brief ischemic periods in neurons can initiate a complex sequence of events that may ultimately culminate in cell death. Different brain regions have varying thresholds for ischemic cell damage, with the white matter being more resilient than the gray matter [1]. Discontinuation of aerobic metabolism due to cerebral ischemia provokes the immediate loss of energy substrates, promotes anaerobic glycolysis with the accumulation of intracellular lactic acid and $\mathrm{H}^{+}$, leading to intracerebral acidosis. Under conditions of hyperglycemia, intracerebral acidosis is exaggerated. Furthermore, there is a loss of energy-dependent ion homeostasis primarily caused by the inhibition of the plasma membrane ATPdependent $\mathrm{Na}^{+} / \mathrm{K}^{+}$exchanger, resulting in an increase in extracellular $\mathrm{K}^{+}$as well as intracellular $\mathrm{Na}^{+}$, leading to cellular depolarization. The ion gradients that are normally established across the plasma membrane have many functions, for example, they are used for the removal of excess intracellular $\mathrm{Ca}^{2+}$ as well as for the re-uptake of extracellular glutamate. These functions are abolished during ischemia. Moreover, $\mathrm{Ca}^{2+}$ influx via voltage-dependent $\mathrm{Ca}^{2+}$ channels can contribute to the release of glutamate from presynaptic terminals to the extracellular space [20]. The excessive release of glutamate further provokes an increase in intracellular $\mathrm{Ca}^{2+}$ and $\mathrm{Na}^{+}$levels by the binding of glutamate to its postsynaptic receptors (i.e., $N$-methyl$D$-aspartate [NMDA] receptors and $\alpha$-amino-3-hydroxy5-methylisoxazole-4-propionic acid [AMPA] receptors). During ischemia, extracellular calcium concentration (Ca)e decreases abruptly from about $1.2 \mathrm{mM}$ to about $0.2 \mathrm{mM}$, demonstrating that virtually all extracellular $\mathrm{Ca}^{2+}$ is taken up by cells [21-23]. This increase in intracellular $\mathrm{Ca}^{2+}$ and $\mathrm{Na}^{+}$levels activates the signal transduction pathways mediated by the activation of $\mathrm{Ca}^{2+}$-dependent enzymes including nitric oxide synthase, phospholipase A2, and calmodulin kinase, which then trigger the following intracellular events: degradation of lipid membrane components, an increase in the levels of free fatty acids, alteration of gene expression, alteration of the phosphorylation and de-phosphorylation state of proteins, degradation of proteins of the cytoskeleton, enzymatic and mitochondrial production of free radicals such as ROS (e.g., superoxide, hydroxyl radicals, and hydrogen peroxide $\left.\left(\mathrm{H}_{2} \mathrm{O}_{2}\right)\right)$ or reactive nitrogen species (Fig. 1). In addition,

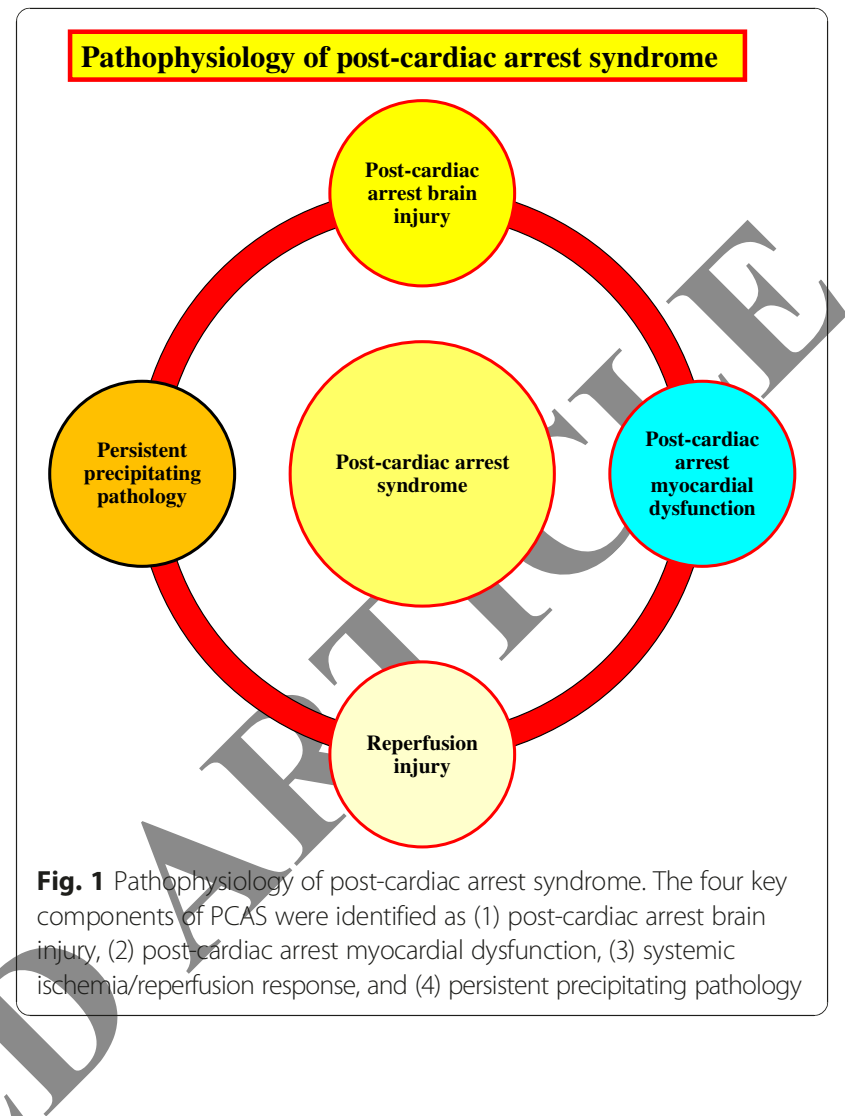

the increased intracellular $\mathrm{Ca}^{2+}$ levels will trigger mitochondrial dysfunction (described separately below and in Fig. 2). This results in the deterioration of neuronal cell membranes and organelles, induction of downstream cascades involving increased $\mathrm{Ca}^{2+}$ cycling and $\mathrm{Ca}^{2+}$ overload (calcium dysregulation), activation of suicide programs, disturbance of axonal transport, activation of macrophages by the expression of adhesion factors, and platelet aggregation associated with microvascular dysfunction, which will eventually lead to unavoidable cell death (Fig. 3). Clinical manifestations of rapid or delayed neuronal degeneration may occur.

This glutamate- $\mathrm{Ca}^{2+}$ theory of excitotoxic neuronal cell death is widely accepted [24-26]. According to this theory, the most important aspect of the pathogenesis of cerebral ischemia is the restriction of substrates and oxygen to the mitochondrial respiratory system and the induction of cellular ATP crisis. It is the loss of cellular energy and its repercussions that trigger acute or delayed neuronal cell death. However, recent analyses of the role played by heart and liver mitochondria in reperfusion injury $[27,28]$ strongly indicate that direct calcium-triggered mitochondrial dysfunction and neuronal cell death associated with the induction of the MPT may be involved in reperfusion injury under situations of decreased cellular energy levels (lowered levels of ATP) and increased oxidative stress (Fig. 4). During the last 


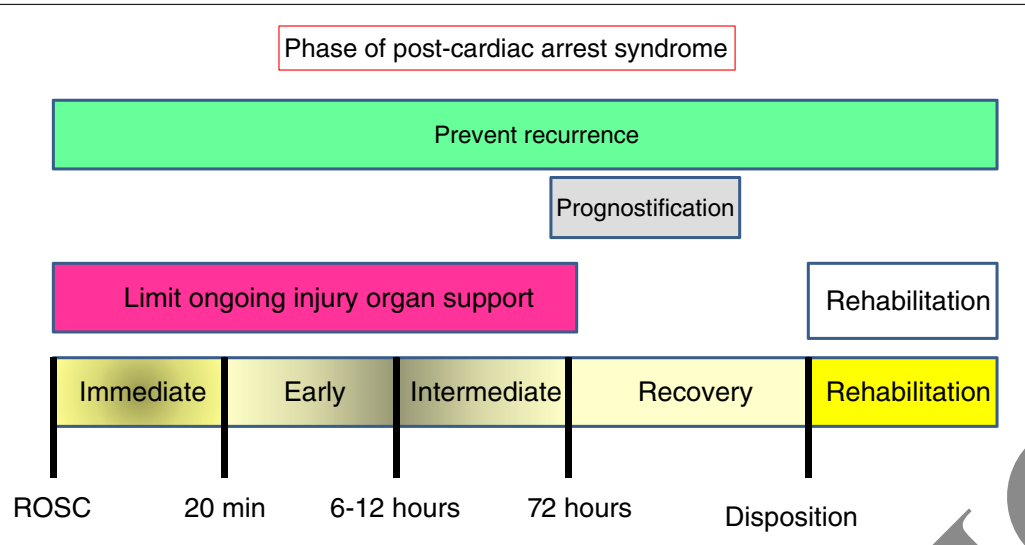

Fig. 2 Relationship to the site of post-cardiac arrest care. Patients with ROSC receive $>20$-min care during transport or in the ED before hospital admission. The first $20 \mathrm{~min}$ after ROSC is defined as the immediate post-arrest phase. Between $20 \mathrm{~min}$ and $6-12 \mathrm{~h}$ after ROSC is defined as the early post-arrest phase. Between 6 and 12 and $72 \mathrm{~h}$ is defined as the intermediate phase. A period beyond 3 days is defined as the recovery phase when prognostification becomes more reliable (cited and modified from Noran 2009)

10 years, we have investigated and characterized the MPT in isolated mitochondria from the CNS as well as examined the role of inhibitors of the MPT in in vivo models of brain disease. The MPT is an exciting new putative therapeutic target for intervention in ischemia reperfusion injury $[3,8,21,29-36]$.

\section{Post-cardiac arrest myocardial dysfunction}

Post-cardiac arrest myocardial dysfunction also contributes to the low survival rate [37]; however, this phenomenon is both responsive to therapy and reversible $[13,38]$. Heart rate and blood pressure are extremely variable due to the transient increase in local

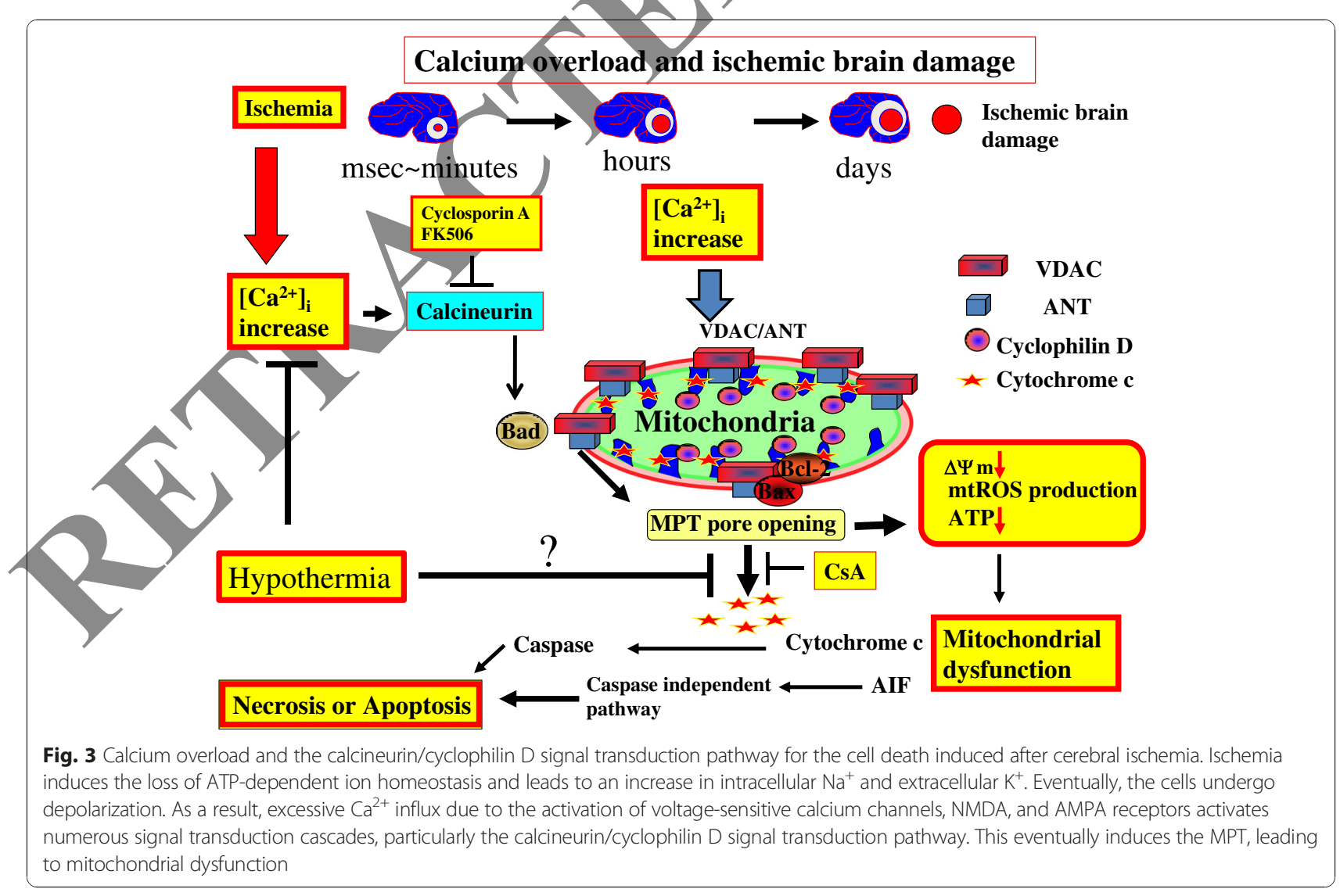




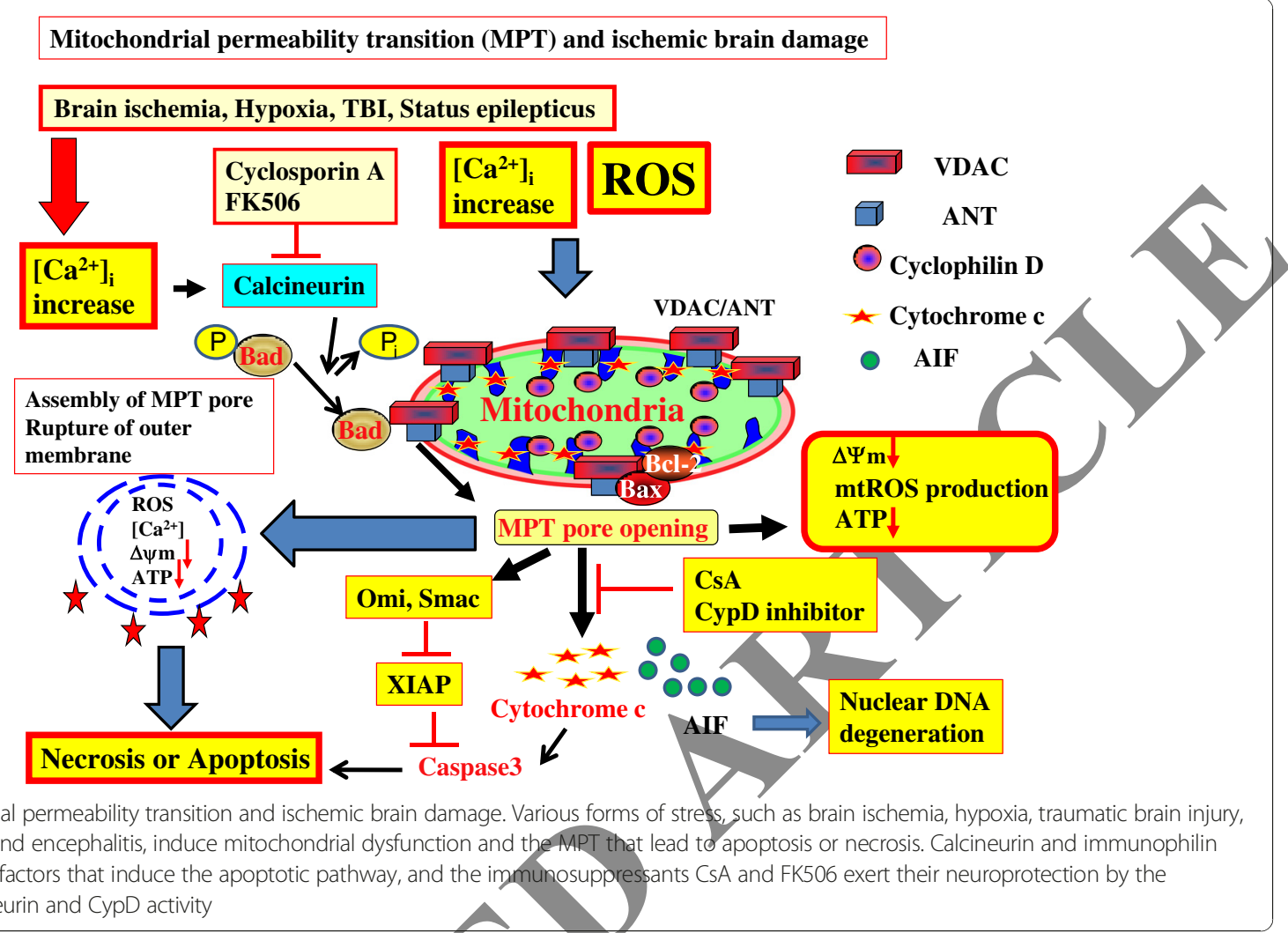

and circulating catecholamine concentrations after ROSC [39]. In one series of 148 patients who underwent coronary angiography after cardiac arrest, $49 \%$ of the subjects had myocardial dysfunction manifested by tachycardia and elevated left ventricular end-diastolic pressure, followed approximately $6 \mathrm{~h}$ later by hypotension (MAP $<75 \mathrm{mmHg}$ ) and low cardiac output (cardiac index $<2.2 \mathrm{~L} \mathrm{~min}^{-1} \mathrm{~m}^{-2}$ ) [13]. Several case series have described transient myocardial dysfunction after human cardiac arrest. Cardiac index values reached their nadir at $8 \mathrm{~h}$ after resuscitation, improved substantially by $24 \mathrm{~h}$, and almost uniformly returned to normal by $72 \mathrm{~h}$ in patients who survived OHCA [13]. The responsiveness of post-cardiac arrest global myocardial dysfunction to inotropic drugs is well documented in animal studies [38, 40].

Reperfusion injury and reactive oxygen species (ROS) It is well known that reperfusion following brain ischemia induces the production of a large amount of ROS ubiquitously throughout a cell. Cardiac arrest represents the most severe shock state, during which delivery of oxygen and metabolic substrates is abruptly halted and metabolites are no longer removed. CPR only partially reverses this process, achieving cardiac output and systemic oxygen delivery $\left(\mathrm{DO}_{2}\right)$ that is much less than normal. During CPR, a compensatory increase in systemic oxygen extraction occurs, leading to significantly decreased central $\left(\mathrm{ScvO}_{2}\right)$ or mixed venous oxygen saturation [22]. The whole-body ischemia/reperfusion of cardiac arrest with associated oxygen debt causes generalized activation of immunological and coagulation pathways, increasing the risk of multiple organ failure and infection [23, 41, 42]. Activation of blood coagulation without adequate activation of endogenous fibrinolysis is an important pathophysiological mechanism that may contribute to microcirculatory reperfusion disorders $[43,44]$. The stress of total body ischemia/reperfusion affects adrenal function. Although an increased plasma cortisol level occurs in many patients after OHCA, relative adrenal insufficiency, defined as failure to respond to corticotrophin (i.e., $<9 \mu \mathrm{g} \mathrm{mL} \mathrm{m}^{-1}$ increase in cortisol), is common $[45,46]$. Clinical manifestations of a systemic ischemic-reperfusion response include intravascular volume depletion, impaired vasoregulation, impaired oxygen delivery and utilization, and increased susceptibility to infection.

A potentially devastating sequence of reperfusion events is one in which resumption of oxygen supply leads to grossly enhanced production of ROS and, thereby, leads to free radical-mediated damage. The restoration of cerebral blood flow, which is known as "reperfusion," elicits multiple cellular and physiologic events. Reperfusion reverses the disruption of cellular functions that was induced by ischemia. In adults, ischemic insults to the 
brain typically result from stroke (caused by either thrombotic occlusion or rupture of a blood vessel) [47] or cardiac arrest [48], whereas in infants, cerebral ischemia can be initiated by complications during delivery, resulting in neonatal hypoxic-ischemic encephalopathy [49]. Spontaneous reperfusion or reperfusion created by an intervention can cause additional and substantial brain damage, which is referred to as "reperfusion injury." Reperfusion induces pathological events such as lipid peroxidation due to the elevation of ROS, inflammation, and calcium overload (calcium dysregulation) that leads to MPT associated with mitochondrial dysfunction [27, 28, 50, 51] (further discussed below).

There are a number of possible cellular sources of these free radicals, including xanthine oxidase, cyclooxygenase, lipoxygenase, cytochrome p450, endothelial nitric oxide synthase, and NADPH oxidase. Mitochondria also produce ROS in the form of a superoxide anion $\left(\mathrm{O}^{2-}\right), \mathrm{H}_{2} \mathrm{O}_{2}$, and hydroxyl radical $\left(\mathrm{OH}^{-}\right)$which have been suggested to play important roles in the regulation of signal transduction and cellular metabolism [52]. Alterations of phosphorylating (state 3) and basal (state 4) respiration and respiratory control indicate a normalization of the electron transport system after reperfusion. However, secondary mitochondrial dysfunction is a prominent consequence of transient cerebral ischemia [53] resulting in a reduction of mitochondrial ATP synthesis. The other major target of ROS is lipids, and the peroxidative action of ROS promotes the inactivation of key metabolic enzymes that regulate glucose metabolism. ROS are inactivated by endogenous mitochondral and cytoplasmic scavenging systems. However, ischemic reperfusion can sometimes overwhelm these scavenging systems, resulting in the production of ROS originating primarily from mitochondrial complexes I and III of the electron transport chain, causing oxidative damage to the mitochondria and consequently the cell [54]. Other highly reactive free radicals are produced by protein nitrosylation due to the reaction of $\mathrm{N} \varnothing$ and superoxide anions, which can also lead to the dysregulation of cellular homeostasis.

\section{Persistent precipitating pathology}

Diagnosis and management of persistent precipitating pathologies such as acute coronary syndrome (ACS), pulmonary diseases, hemorrhage, sepsis, and various toxic syndromes can complicate and be complicated by the simultaneous pathophysiology of PCAS. Consecutive patients had no obvious non-cardiac etiology but had undergone coronary angiography after resuscitation from OHCA [55]. Nine of the patients with acute coronary occlusion did not have chest pain or ST segment elevation. Elevations in troponin $\mathrm{T}$ measured during treatment of cardiac arrest suggest that ACS precedes OHCA in $40 \%$ of the patients [56]. Another thromboembolic disease to consider after cardiac arrest is pulmonary embolism. Pulmonary emboli have been reported in $2-10 \%$ of sudden deaths $[57,58]$.

Primary pulmonary diseases such as chronic obstructive pulmonary disease, asthma, or pneumonia can lead to respiratory failure and cardiac arrest. When cardiac arrest is caused by respiratory failure, pulmonary physiology may be worse after restoration of circulation. Redistribution of blood into pulmonary vasculature can lead to frank pulmonary edema or at least increased alveolar-arterial oxygen gradients after cardiae arrest [59]. Acute brain edema is more common after cardiac arrest caused by asphyxia [60]. It is possible that perfusion with hypoxemic blood during asphyxia preceding complete circulatory collapse is harmful.

Sepsis is a cause of cardiac arrest, acute respiratory distress syndrome, and multiple organ failure. Thus, there is a predisposition for exacerbation of PCAS when cardiac arrest occurs in the setting of sepsis. Other precipitating causes of cardiac arrest may require specific treatment during the post-cardiac arrest period. For example, drug overdose and intoxication may be treated with specific antidotes, and environmental causes such as hypothermia may require active temperature control.

\section{Disturbance of mitochondrial $\mathrm{Ca}^{2+}$ homeostasis in} neurons

During ischemia, neuronal $\mathrm{Ca}^{2+}$ channels and transporters as well as glutamate receptors are overactivated, and the increased activity of plasma membrane $\mathrm{Ca}^{2+}$ channels can then trigger the entry of $\mathrm{Ca}^{2+}$ into the cytosol, leading to $\mathrm{Ca}^{2+}$ overload. Mitochondria contain two membranes, an outer membrane permeable to solutes and an inner membrane impermeable to solutes that harbors the respiratory chain complexes. Mitochondria powerfully sequester $\mathrm{Ca}^{2+}$ to prevent the elevation of cytosolic $\mathrm{Ca}^{2+}$, but prolonged depolarization and $\mathrm{Ca}^{2+}$ influx lead to mitochondrial $\mathrm{Ca}^{2+}$ overload. Mitochondrial $\mathrm{Ca}^{2+}$ overload is induced by three mechanisms: (i) increased mitochondrial $\mathrm{Ca}^{2+}$ uptake following the release of $\mathrm{Ca}^{2+}$ from the endoplasmic reticulum and $\mathrm{Ca}^{2+}$ influx from the extracellular space, (ii) reduced $\mathrm{Ca}^{2+}$ extrusion through the mitochondrial $\mathrm{Na}^{+} / \mathrm{Ca}^{2+}$ exchanger, and (iii) changes in the capacity of mitochondrial $\mathrm{Ca}^{2+}$ buffering [61]. Moderate increases in mitochondrial $\mathrm{Ca}^{2+}$ concentration are necessary and sufficient to adjust ATP production to cell demand, but mitochondrial $\mathrm{Ca}^{2+}$ overload leads to the MPT, which causes the disruption of mitochondrial membrane integrity, irreversible oxidative damage, and the loss of ATP production, finally resulting in cell death. This may be achieved by altering the redox state, decreasing energy demand, or supplying the cells with pharmacological inhibitors of the MPT, such as cyclophilin inhibitors [62] (see also below). 


\section{Inflammation}

This phenomenon occurs very rapidly and is more robust during reperfusion. The inflammatory reaction of the blood vessels occurs immediately after vessel occlusion and induces the activation of platelets and endothelial cells. The expression of adhesion molecules including selectins, intercellular adhesion molecules, and vascular cell adhesion molecules is induced by the adhesion of neutrophils initially and then later monocytes to the endothelium. Brain ischemia induces an inflammatory reaction that leads to mitochondrial damage [63]. Activated leukocytes contribute to blood vessel occlusion, which disturbs vascular patency and releases proinflammatory cytokines, proteases, and ROS that induce vascular damage at the endothelial surface, leading to thrombus formation, vasospasm, and breakdown of the blood-brain barrier, further promoting the infiltration of leukocytes into the brain. Activation of microglia, which are the resident tissue macrophages, occurs within minutes of the onset of ischemia. After neuronal cell death, danger-associated molecular pattern molecules activate the pattern recognition receptors, including the Toll-like receptors expressed on microglia, and contribute to the inflammatory response in brain ischemia. Microglia also produce ROS that can cause mutations in mitochondrial DNA and damage the enzymes of the respiratory chain, leading to dysfunction of oxidative phosphorylation and increased ROS production [64]. The early inflammatory response therefore appears to induce the secondary failure of bioenergetic function.

\section{Molecular mechanisms of the mitochondrial permeability} transition (MPT)

The MPT was traditionally considered to be mediated by the formation of an MPT pore, which is a dynamic complex of several proteins. This protein complex was proposed to be located at the contact sites between the inner and outer mitochondrial membranes, which are sites important for metabolic regulation as well as interaction with the cytosol, intermembrane space, and the matrix compartments $[65,66]$. It is still unclear whether the elevation of mitochondrial matrix $\mathrm{Ca}^{2+}$ levels during ischemia is causally related to the neuronal cell death that occurs after cerebral ischemia. The current general hypothesis is that the MPT is formed by the voltagedependent anion channel (VDAC or porin) of the outer membrane, the adenine nucleotide translocase (ANT) of the inner membrane, and cyclophilin D (CypD) located in the matrix compartment [66]. However, a recent gene deletion study has questioned the role of VDAC as an essential component and regulator of the MPT [67].

The increased permeability of the inner mitochondrial membrane can also possibly be induced by the concerted action of other proteins such as the uncoupling proteins and the Tom/Tim transport system, as well as by the aggregation of misfolded membrane proteins. However, the proposed core components of the MPT pore, in particular ANT and CypD, are likely to be the proteins involved in the MPT phenomenon during calcium overload under pathophysiological conditions. Hansson et al. reported that adult-viable human brain and liver mitochondria possess an active CypD-sensitive mtPTP and that CypD inhibition plays animportant role for neuroprotection [68-70].

In summary, the obligate molecular components of the MPT have not yet been resolved. Initially, there was the hypothesis that the MPT requires a complex consisting of the inner membrane protein ANT, the outer membrane component VDAC/porin, and the matrix modulator CypD.

\section{Critical role of the MPT in neurodegeneration}

The loss of ATP, an increase in the levels of calcium, phosphate, and free fatty acids; and the generation of free radicals are key factors in inducing the MPT (Fig. 4). The proton gradient and the mitochondrial membrane potential $(\Delta \Psi \mathrm{m})$ are rapidly lost as the hydrogen ions extruded from the mitochondria by the electron transport chain rapidly fall back through the MPT pores, uncoupling oxidation of metabolic substrates and respiration from the phosphorylation of ADP. The consequences of the MPT are dramatic when the inner membrane rapidly becomes permeable to solutes of up to $1500 \mathrm{Da}$ (Fig. 4). Importantly, this transition, if prolonged, can affect respiration in different ways according to the substrate being oxidized. Induction of the MPT in mitochondria energized with complex-I-linked substrates is followed by complete respiratory inhibition due to the loss of pyridine nucleotides [71, 72]. Induction of the MPT in mitochondria energized with complex-II-linked substrates is followed by uncoupling. The mitochondrial matrix is dense in proteins, and the induction of the MPT pores will result in an osmotic influx of water into the matrix, causing the inner membrane to unfold and expand, resulting in mitochondrial swelling, as well as causing the outer membrane to rupture, inducing the release of proapoptotic proteins such as cytochrome c $[73,74]$ and apoptosis-inducing factors Omi and Smac (Fig. 4). Prolonged and extensive MPT will lead to the termination of ATP production and necrotic cell death, if the energy balance cannot be compensated by anaerobic metabolism.

\section{Calcineurin and cell death}

Calcineurin was first discovered by Wang et al. in 1976 as an inhibitor of calmodulin (CaM)-dependent cyclic phosphodiesterase [75]. Calcineurin is abundantly distributed in the hippocampus, striatum, and cerebral 
cortex. Subcellularly, it is primarily found bound to the cell membrane or the cytoskeletal elements and is enriched in postsynaptic densities. Calcineurin is best known as being a target for the widely used immunosuppressive molecules cyclosporin-A (CsA) and tacrolimus (FK506) [76]. Under physiological conditions, the effects of calcineurin are greatly multifaceted, for example, it can dephosphorylate NMDA receptors, IP3 receptors, and ryanodine receptors, which are all relevant to the regulation of intracellular $\mathrm{Ca}^{2+}$ levels. Shibasaki et al. demonstrated the interaction between members of the antiapoptotic $\mathrm{Bcl}-2$ protein family and calcineurin activity, indicating an important role for calcineurin in the regulation of apoptosis [77]. They furthermore demonstrated that calcineurin specifically participates in $\mathrm{a} \mathrm{Ca}^{2+}$-inducible mechanism for apoptosis induction by regulating $\mathrm{BAD}$ (a proapoptotic $\mathrm{Bcl}-2$ protein family member) phosphorylation [78] (see Fig. 4).

\section{Conclusions}

Mechanisms of brain injury due to cardiac arrest and delayed neuronal death that occurs over hours to days after ROSC remain unknown. The pathophysiology of PCAS involves a complex cascade of molecular events, most of which are still unknown. Many lines of research evidence have shown that mitochondria suffer severe damage in response to ischemic injury. Mitochondrial dysfunction based on the MPT after reperfusion, particularly involving the calcineurin/immunophilin signal transduction pathway, appears to play a critical role in the induction of brain injury following cardiac arresst.

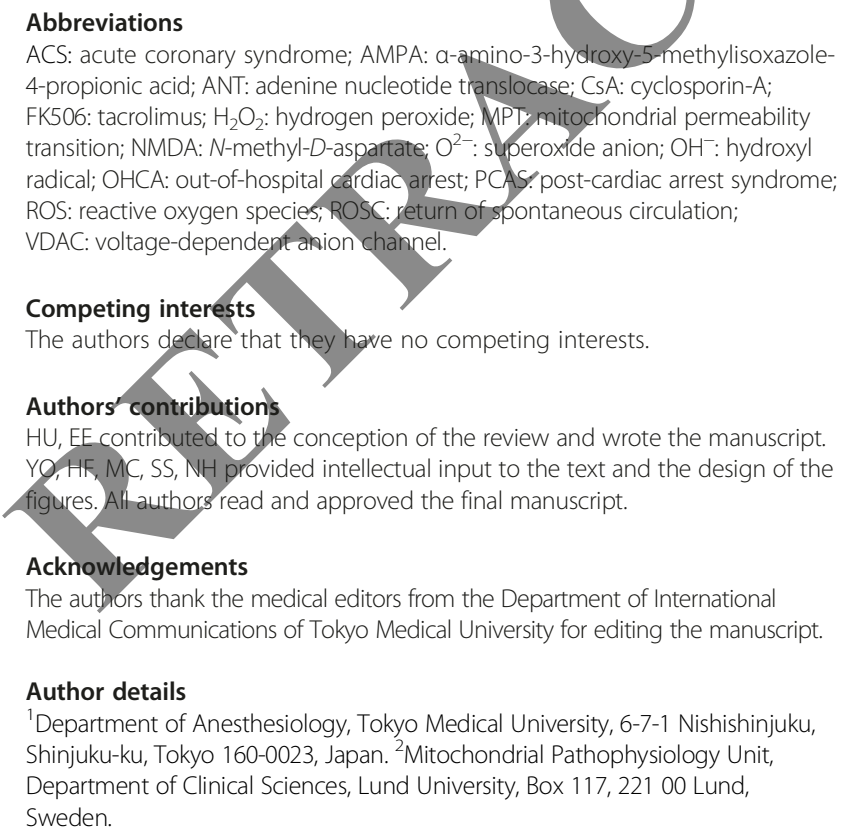

\section{Author details}

'Department of Anesthesiology, Tokyo Medical University, 6-7-1 Nishishinjuku, Shinjuku-ku, Tokyo 160-0023, Japan. ${ }^{2}$ Mitochondrial Pathophysiology Unit, Department of Clinical Sciences, Lund University, Box 117, 22100 Lund, Sweden.

Received: 28 September 2015 Accepted: 4 February 2016 Published online: 27 April 2016

\section{References}

1. Peberdy MA, Callaway CW, Neumar RW, Geocadin RG, Zimmerman JL, Donnino M, et al. Part 9: post-cardiac arrest care: 2010 American Heart Association guidelines for cardiopulmonary resuscitation and emergency cardiovascular care. Circulation. 2010;122:S768-86.

2. Uchino H, Elmér E, Uchino K, Lindvall O, Siesjö BK. Cyclosporin A dramatically ameliorates CA1 hippocampal damage following transient forebrain ischaemia in the rat. Acta Physiol Scand. 1995;155(4):469-71.

3. Uchino $\mathrm{H}$, Kuroda Y, Morota S, Hirabayashi G, Ishii N, Shibasaki F, Hansson MJ, Elmér E.Probing the molecular mechanisms of heuro activation. J Anesth. 2008;22(3):253-62

4. Cho TH, Aguettaz P, Campuzano O, Charriaut-Marlangue C, Riou A Berthezène $Y$, et al. Pre- and post-treatment with cyclosporine $A$ in a rat model of transient focal cerebral ischaemia with multimodal MRI screening. Int J Stroke. 2013;8(8):669-74. doi:10.1111/j.1747-4949.2012.00849.x. Epub 2012 Aug 7.

5. Mbye LH, Singh IN, Carrico KM, Saatnan KE, Hall ED. Comparative neuroprotective effects of cyclosporin A and NIM811, a nonimmunosuppressive cyclosporin A analog, following traumatic brain injury. J Cereb Blood Flow Metab. 2009:29(1):87-97. do1:10.1038/jcbfm.2008.93. Epub 2008 Aug 20.

6. Sullivan $P G$, Sebastian $A H$, Hall ED. Therapeutic window analysis of the neuroprotective effects of cyclosporine $A$ after traumatic brain injury. J Neurotrauma 2011;28(2).311-8. doi:10.1089/neu.2010.1646. Epub 2011 Feb 2.

7. Popp E, Bottiger BW. Cerebral resuscitation: state of the art, experimental approaches and clinical perspectives. Neurol Clin. 2006;24(1):73-87. doi:10.1016/j.ncl.2005.10.008. vi.

8. Siesjo BK, Siesjo P. Mechanisms of secondary brain injury. Eur J Anaesthesiol. 1996;13(3):247-68)

9. Crompton M. The mitochondrial permeability transition pore and its role in cell death. Biochem J. 1999;341(Pt 2):233-49.

10. Friberg $\mathrm{H}$, Wieloch $\mathrm{T}$. Mitochondrial permeability transition in acute neurodegeneration. Biochimie. 2002;84(2-3):241-50.

kroemer G. The mitochondrial permeability transition pore complex as a pharmacological target. An introduction. Curr Med Chem. 2003;10(16):1469-72. Wieloch T, Mattiasson G, Hansson MJ, Elmér E. Mitochondrial permeability transition in the CNS - composition, regulation, and pathophysiological relevance. Handbook of Neurochemistry and Molecular Neurobiology - Brain Energetics. Integration of Molecular and Cellular Processes. 3 ed. Berlin: Springer. 2007. p. 667-702.

13. Laurent I, Monchi M, Chiche JD, Joly LM, Spaulding C, Bourgeois B, et al. Reversible myocardial dysfunction in survivors of out-of-hospital cardiac arrest. J Am Coll Cardiol. 2002:40(12):2110-6.

14. Gazmuri RJ, Becker J. Cardiac resuscitation. The search for hemodynamically more effective methods. Chest. 1997;111(3):712-23.

15. Ristagno G, Tang W, Huang L, Fymat A, Chang YT, Sun S, et al. Epinephrine reduces cerebral perfusion during cardiopulmonary resuscitation. Crit Care Med. 2009;37(4):1408-15. doi:10.1097/CCM.0b013e31819cedc9.

16. Chalkias A, Xanthos T. Pathophysiology and pathogenesis of postresuscitation myocardial stunning. Heart Fail Rev. 2012;17(1):117-28. doi:10.1007/s10741-011-9255-1.

17. Goldhaber Jl, Qayyum MS. Oxygen free radicals and excitation-contraction coupling. Antioxid Redox Signal. 2000;2(1):55-64.

18. Huet O, Dupic L, Batteux F, Matar C, Conti M, Chereau C, et al. Postresuscitation syndrome: potential role of hydroxyl radical-induced endothelial cell damage. Crit Care Med. 2011;39(7):1712-20. doi:10.1097/ CCM.0b013e3182186d42

19. Xu K, Puchowicz MA, Sun X, LaManna JC. Decreased brainstem function following cardiac arrest and resuscitation in aged rat. Brain Res. 2010;1328:181-9. doi:10.1016/j.brainres.2010.02.080

20. Meldrum BS. Glutamate as a neurotransmitter in the brain: review of physiology and pathology. J Nutr. 2000;130(4S Suppl):1007S-15S.

21. Hansson MJ, Persson T, Friberg H, Keep MF, Rees A, Wieloch T, et al. Powerful cyclosporin inhibition of calcium-induced permeability transition in brain mitochondria. Brain Res. 2003;960(1-2):99-111.

22. Rivers EP, Martin GB, Smithline $H$, Rady MY, Schultz $C H$, Goetting MG, et al. The clinical implications of continuous central venous oxygen saturation during human CPR. Ann Emerg Med. 1992;21(9):1094-101.

23. Cerchiari EL, Safar P, Klein E, Diven W. Visceral, hematologic and bacteriologic changes and neurologic outcome after cardiac arrest in dogs. The visceral post-resuscitation syndrome. Resuscitation. 1993;25(2):119-36. 
24. Choi DW. Excitotoxic cell death. J Neurobiol. 1992;23(9):1261-76. doi:10.1002/neu.480230915.

25. Dirnagl U, ladecola C, Moskowitz MA. Pathobiology of ischaemic stroke: an integrated view. Trends Neurosci. 1999;22(9):391-7.

26. Mattson MP. Excitotoxic and excitoprotective mechanisms: abundant targets for the prevention and treatment of neurodegenerative disorders. Neuromolecular Med. 2003;3(2):65-94. doi:10.1385/NMM:3:2:65.

27. Halestrap AP. The mitochondrial permeability transition: its molecular mechanism and role in reperfusion injury. Biochem Soc Symp. 1999;66:181-203.

28. Honda HM, Korge P, Weiss JN. Mitochondria and ischemia/reperfusion injury. Ann N Y Acad Sci. 2005;1047:248-58. doi:10.1196/annals.1341.022.

29. Terasaki Y, Liu Y, Hayakawa K, Pham LD, Lo EH, Ji X, et al. Mechanisms of neurovascular dysfunction in acute ischemic brain. Curr Med Chem. 2014;21(18):2035-42.

30. Kim JS, He L, Lemasters JJ. Mitochondrial permeability transition: a common pathway to necrosis and apoptosis. Biochem Biophys Res Commun. 2003;304(3):463-70.

31. Halestrap AP, Clarke SJ, Javadov SA. Mitochondrial permeability transition pore opening during myocardial reperfusion-a target for cardioprotection. Cardiovasc Res. 2004;61(3):372-85. doi:10.1016/S0008-6363(03)00533-9.

32. Sullivan PG, Rabchevsky AG, Waldmeier PC, Springer JE. Mitochondrial permeability transition in CNS trauma: cause or effect of neuronal cell death? J Neurosci Res. 2005;79(1-2):231-9. doi:10.1002/jnr.20292.

33. Schinzel AC, Takeuchi O, Huang Z, Fisher JK, Zhou Z, Rubens J, et al. Cyclophilin $\mathrm{D}$ is a component of mitochondrial permeability transition and mediates neuronal cell death after focal cerebral ischemia. Proc Natl Acad Sci U S A. 2005;102(34):12005-10. doi:10.1073/pnas.0505294102.

34. Schneider MD. Cyclophilin D: knocking on death's door. Sci STKE. 2005; 2005(287):e26. doi:10.1126/stke.2872005pe26.

35. Hansson MJ, Mansson R, Mattiasson G, Ohlsson J, Karlsson J, Keep MF, et al. Brain-derived respiring mitochondria exhibit homogeneous, complete and cyclosporin-sensitive permeability transition. J Neurochem. 2004;89(3):715-29. doi:10.1111/j.1471-4159.2004.02400.x.JNC2400.

36. Hansson MJ, Mattiasson G, Mansson R, Karlsson J, Keep MF, Waldmeier P, et al. The nonimmunosuppressive cyclosporin analogs NIM811 and UNIL025 display nanomolar potencies on permeability transitio brain-derived mitochondria. J Bioenerg Biomembr. 2004;36(4):407-13 doi:10.1023/B:JOBB.0000041776.31885.45. 490863.

37. Laver S, Farrow C, Turner D, Nolan J. Mode of death after admission to an intensive care unit following cardiac arrest. 2004;30(11):2126-8. doi:10.1007/s00134-004-2425-z.

38. Huang L, Weil MH, Tang W, Sun S, Wang J. Comparison between dobutamine and levosimendan for management of postresuscitation myocardial dysfunction. Crit Care Med. 2005;33(3):

39. Rivers EP, Wortsman J, Rady MY, Blake HC, MCGeorge, FT, Buderer NM. The effect of the total cumulative epinephrine dose-administered during human CPR on hemodynamic, oxygen transport, and utilization variables in the postresuscitation period. Chest. 1994;106(5):1499-507.

40. Ruiz-Bailen M, de Hoyos Aguayo E, Ruiz-Navarro S, Diaz-Castellanos MA, Rucabado-Aguilar L, Gomez-Jimenez FJ, et al. Reversible myocardial dysfunction after cardiopulmonary resuscitation. Resuscitation. 2005;66(2):175-81. doi:10.1016/j.resuscitation.2005.01.012.

41. Adams JA. Endothelium and Cardiopulmonary resuscitation. Crit Care Med. 2006;34(12 \$uppl):S458-65. doi:10.1097/01.CCM.0000246012.68479.49.

42. Esmon C. Coagulation and inflammation. J Endotoxin Res. 2003:9(3):192-8. doi:10.1179/096805103125001603.

Bottiger BW, Motsch J, Bohrer H, Boker T, Aulmann M, Nawroth PP, et al. Activation of blood coagulation after cardiac arrest is not balanced adequately ion of endogenous fibrinolysis. Circulation. 1995;92(9):2572-8

44. Adrie C, Monchi M, Laurent I, Um S, Yan SB, Thuong M, et al. Coagulopathy after successful cardiopulmonary resuscitation following cardiac arrest: implication of the protein C anticoagulant pathway. J Am Coll Cardiol. 2005;46(1):21-8. doi:10.1016/j.jacc.2005.03.046.

45. Hekimian G, Baugnon T, Thuong M, Monchi M, Dabbane H, Jaby D, et al. Cortisol levels and adrenal reserve after successful cardiac arrest resuscitation. Shock. 2004;22(2):116-9.

46. Schultz CH, Rivers EP, Feldkamp CS, Goad EG, Smithline HA, Martin GB, et al. A characterization of hypothalamic-pituitary-adrenal axis function during and after human cardiac arrest. Crit Care Med. 1993;21(9):1339-47.

47. Lloyd-Jones D, Adams RJ, Brown TM, Carnethon M, Dai S, De Simone G, et al. Heart disease and stroke statistics-2010 update: a report from the
American Heart Association. Circulation. 2010;121(7):e46-e215. doi:10.1161/CIRCULATIONAHA.109.192667.

48. Krause GS, Kumar K, White BC, Aust SD, Wiegenstein JG. Ischemia, resuscitation, and reperfusion: mechanisms of tissue injury and prospects for protection. Am Heart J. 1986;111(4):768-80.

49. Vannucci RC. Hypoxic-ischemic encephalopathy. Am J Perinatol. 2000;17(3):113-20. doi:10.1055/s-2000-9293.

50. Fraser PA. The role of free radical generation in increasing cerebrovascular permeability. Free Radic Biol Med. 2011;5 doi:10.1016/j.freeradbiomed.2011.06.003.

51. Halestrap AP. Calcium, mitochondria and reperfusion injury: a pore way to die. Biochem Soc Trans. 2006;34(Pt 2):232-7. doi:10.1042/BST20060232

52. Broughton BR, Reutens DC, Sobey CG. Apoptotic mechanisms after cerebral ischemia. Stroke. 2009;40(5):e331-9. doi:10.1161/STROKEAHA.108.531632.

53. Sanderson TH, Reynolds CA, Kumar R, Przyklenk K, Huttemann M. Molecular mechanisms of ischemia-reperfusion injury in brain: pivotal Pole of the mitochondrial membrane potential in (reactive oxygen species generation. Mol Neurobiol. 2013;47(1):9-23. dor:10.1007/s12035-012-8344-z.

54. Chen Q, Vazquez EJ, Moghaddas S, Hoppel CL, Lesnefsky EJ. Production of reactive oxygen species by mitochondria: central role of complex III. J Biol Chem. 2003;278(38):36027-31. doi:10.1074/jbc.M304854200.

55. Spaulding CM, Joly LM, Rosenberg A, Monchi M, Weber SN, Dhainaut JF, et al. Immediate coronary angiography in survivors of out-of-hospital cardiac arrest. $N$ Engl J Med. 1997;336(23):1629-33. doi:10.1056/ NEJM199706053362302.

56. Lai CS, Hostler D, D'Cruz BJ, Callaway CW. Prevalence of troponin-T elevation during out-of-hospital cardiac arrest. Am J Cardiol. 2004;93(6):754-6. oi:10.1016/J.amjcard.2003.11.068.

57. Sandler DA Martid JF. Autopsy proven pulmonary embolism in hospital patients: are we detecting enough deep vein thrombosis? J R Soc Med. 1989;82(4):203-5.

58. Courtney DM, Kline JA. Prospective use of a clinical decision rule to identify pulmonary embolism as likely cause of outpatient cardiac arrest. Resuscitation. 2005;65(1):57-64. doi:10.1016/j.resuscitation.2004.07.018.

59. Ornato JP, Ryschon TW, Gonzalez ER, Bredthauer JL. Rapid change in pulmonary vascular hemodynamics with pulmonary edema during cardiopulmonary resuscitation. Am J Emerg Med. 1985;3(2):137-42.

60. Morimoto Y, Kemmotsu O, Kitami K, Matsubara I, Tedo I. Acute brain swelling after out-of-hospital cardiac arrest: pathogenesis and outcome. Crit Care Med. 1993;21(1):104-10.

61. Cali T, Ottolini D, Brini M. Mitochondrial $\mathrm{Ca}(2+)$ and neurodegeneration. Cell Calcium. 2012;52(1):73-85. doi:10.1016/j.ceca.2012.04.015.

62. Halestrap AP, Woodfield KY, Connern CP. Oxidative stress, thiol reagents, and membrane potential modulate the mitochondrial permeability transition by affecting nucleotide binding to the adenine nucleotide translocase. J Biol Chem. 1997;272(6):3346-54.

63. Ahmad M, Dar NJ, Bhat ZS, Hussain A, Shah A, Liu H, et al. Inflammation in ischemic stroke: mechanisms, consequences and possible drug targets. CNS Neurol Disord Drug Targets. 2014;13(8):1378-96.

64. Di Filippo M, Chiasserini D, Tozzi A, Picconi B, Calabresi P. Mitochondria and the link between neuroinflammation and neurodegeneration. J Alzheimers Dis. 2010;20 Suppl 2:S369-79. doi:10.3233/JAD-2010-100543.

65. Knoll G, Brdiczka D. Changes in freeze-fractured mitochondrial membranes correlated to their energetic state. Dynamic interactions of the boundary membranes. Biochim Biophys Acta. 1983;733(1):102-10.

66. Crompton M, Barksby E, Johnson N, Capano M. Mitochondrial intermembrane junctional complexes and their involvement in cell death. Biochimie. 2002;84(2-3):143-52.

67. Baines CP, Kaiser RA, Purcell NH, Blair NS, Osinska H, Hambleton MA, et al. Loss of cyclophilin D reveals a critical role for mitochondrial permeability transition in cell death. Nature. 2005;434(7033):658-62. doi:10.1038/nature03434.

68. Gajavelli S, Sinha VK, Mazzeo AT, Spurlock MS, Lee SW, Ahmed Al, et al. Evidence to support mitochondrial neuroprotection, in severe traumatic brain injury. J Bioenerg Biomembr. 2015;47(1-2):133-48. doi:10.1007/ s10863-014-9589-1.

69. Hansson MJ, Morota S, Chen L, Matsuyama N, Suzuki Y, Nakajima S, et al. Cyclophilin D-sensitive mitochondrial permeability transition in adult human brain and liver mitochondria. J Neurotrauma. 2011;28(1):143-53. doi:10.1089/neu.2010.1613.

70. Uchino H, Hatakeyama K, Morota S, Tanoue T, Nishiyama T, Usui D, et al. Cyclophilin-D inhibition in neuroprotection: dawn of a new era of 
mitochondrial medicine. Acta Neurochir Suppl. 2013;118:311-5. doi:10.1007/978-3-7091-1434-6_61.

71. Vinogradov A, Scarpa A, Chance B. Calcium and pyridine nucleotide interaction in mitochondrial membranes. Arch Biochem Biophys. 1972;152(2):646-54.

72. Hunter DR, Haworth RA, Southard JH. Relationship between configuration, function, and permeability in calcium-treated mitochondria. J Biol Chem. 1976;251(16):5069-77.

73. Hirakawa A, Takeyama N, Nakatani T, Tanaka T. Mitochondrial permeability transition and cytochrome $\mathrm{c}$ release in ischemia-reperfusion injury of the rat liver. J Surg Res. 2003;111(2):240-7.

74. Takeyama N, Miki S, Hirakawa A, Tanaka T. Role of the mitochondrial permeability transition and cytochrome $C$ release in hydrogen peroxideinduced apoptosis. Exp Cell Res. 2002;274(1):16-24.

75. Wang JH, Desai R. A brain protein and its effect on the $\mathrm{Ca} 2+-$ and protein modulator-activated cyclic nucleotide phosphodiesterase. Biochem Biophys Res Commun. 1976;72(3):926-32.

76. Liu J, Farmer Jr JD, Lane WS, Friedman J, Weissman I, Schreiber SL. Calcineurin is a common target of cyclophilin-cyclosporin A and FKBP-FK506 complexes. Cell. 1991;66(4):807-15.

77. Shibasaki F, Kondo E, Akagi T, McKeon F. Suppression of signalling through transcription factor NF-AT by interactions between calcineurin and Bcl-2. Nature. 1997;386(6626):728-31. doi:10.1038/386728a0.

78. Wang HG, Pathan N, Ethell IM, Krajewski S, Yamaguchi Y, Shibasaki F, et al. $\mathrm{Ca}^{2+}$-induced apoptosis through calcineurin dephosphorylation of BAD. Science. 1999;284(5412):339-43.

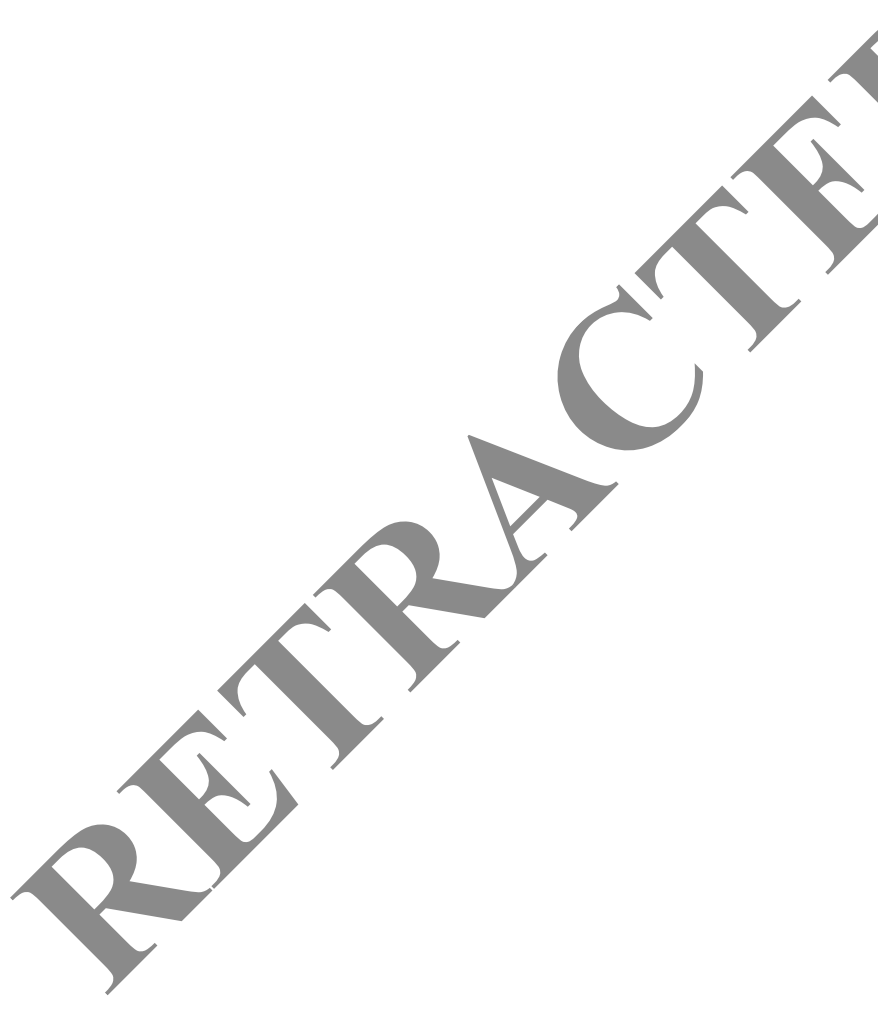

Submit your next manuscript to BioMed Central and we will help you at every step:

- We accept pre-submission inquiries

- Our selector tool helps you to find the most relevant journal

- We provide round the clock customer support

- Convenient online submission

- Thorough peer review

- Inclusion in PubMed and all major indexing services

- Maximum visibility for your research

Submit your manuscript at www.biomedcentral.com/submit 